\title{
SRBIJA I AKTUELNI GEOPOLITIČKI PROCESI NA BALKANU*
}

\author{
Miša Stojadinović** \\ Institut za političke studije, Beograd \\ Violeta Rašković Talović*** \\ Univerzitet „Union - Nikola Tesla“, \\ Fakultet za međunarodnu politiku i bezbednost, Beograd
}

\begin{abstract}
Depublika Srbija je kraj XX veka dočekala kao slaba i nedovršena Idržava izložena snažnim pritiscima velikih sila, procesima regionalne nestabilnosti i brojnim dezintegrativnim tendencijama uz stalno prekrajanje njenih granica. U ovom radu se razmatraju aktuelni geopolitički izazovi koji se nameću pred Republiku Srbiju u pokušaju da pronađe svoje mesto u procesu međunarodnih integracija. Predmet ovog rada je analiza mogućnosti jačanja regionalne saradnje kao jednog od najznačajnijih načina da balkanske države prevaziđu konstantnu sukobljenost Istoka i Zapada na ovim prostorima. Takođe, u radu se analizira pozicija Srbije kroz izazove sa kojima se suočavaju sve balkanske zemlje, pokazujući da bi od poboljšanja regionalne saradnje sve one imale koristi u smislu jačanja svoje pozicije u međunarodnim odnosima. Kao najveći izazov ovome nameće se nedostatak multilateralne saradnje uz prevelik broj dugogodišnjih nerešenih nesuglasica i konflikata. Rad se oslanja na geopolitički pristup razumevanju međunarodnih odnosa uz korišćenje istorijskog, geografskog i komparativnog metoda.
\end{abstract}

Ključne reči: geopolitika, međunarodne integracije, političke institucije, Balkan, Republika Srbija

\section{Geopolitički izazovi Balkana u XXI veku}

sidora Sekulić, čuvena srpska književnica, romanopisac, poliglota, likovni kritičar i akademik, je za Balkan pisala da predstavlja jedan zaseban svet: „Države i narodi na njemu, kao u jedan brod ukrcan, moraju imati jedan opšti politički problem i politički ideal, ma koliko inače raznovrsni bili. Balkan dolazi u obzir pre svih država na Balkanu, kada god je momenat težak i opasan, svejedno da li opasan politički ili kulturno. Hoće li Balkan jedared otvoriti oči uspavane i videti svoj ogromni kulturni kapacitet, ako zamah-

\footnotetext{
* Rad je nastao kao rezultata rada na projektu br. 179009 koji je finansiran od strane Ministarstva prosvete, nauke i tehnološkog razvoja Republike Srbije.

** Dr Miša Stojadinović je viši naučni saradnik.

**** Prof. dr Violeta Rašković Talović je dekan Fakulteta za međunarodnu politiku i bezbednost.
} 
ne kao celina?" ${ }^{11}$ Međutim, ono što se dešava kao najveći problem ostvarivanja dijaloga i saradnje na Balkanu je to što su upravo razlike između država te koje se uglavnom stavljaju u prvi plan, dok su sličnosti u potpunosti zanemarene. To je glavni razlog zbog koga konflikt na Balkanu predstavlja konstantu tokom čitave njegove istorije. Kapacitet Balkanskih država je zaista zapanjujući, ali uprkos tome on je neretko zloupotrebljen u kontekstu interesa velikih sila. $U$ dugoj istoriji konflikata na ovim prostorima je bilo isuviše besmislenih ratova i previše života je izgubljeno. Sama kompleksnost prirode Balkana se može videti čak i u problemu određivanja njegovih granica (Slika 1).

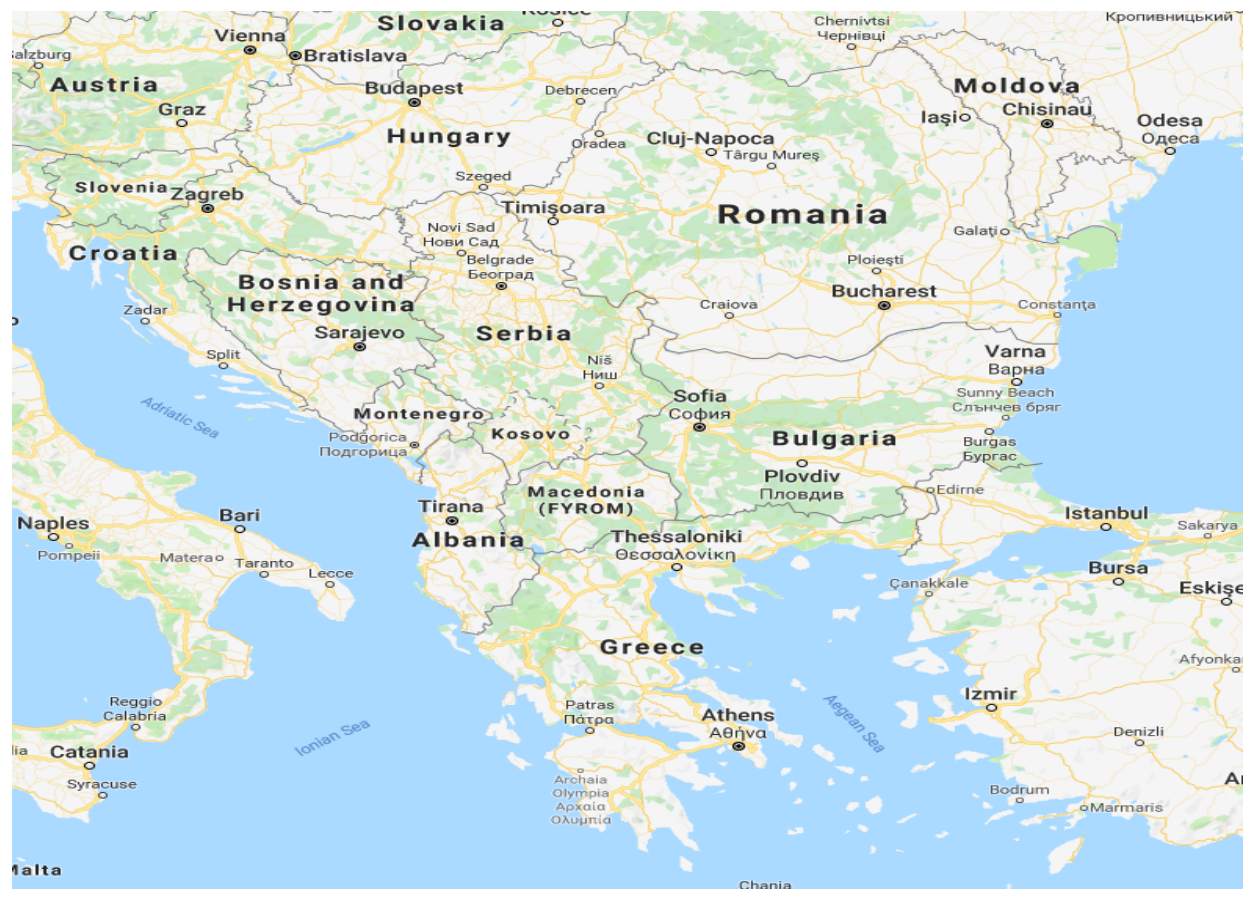

Slika 1 - Balkansko poluostrvo

(Izvor: Google Maps, https://www.google.com/maps/place/Balkans)

Situacija se značajno usložnjava sa činjenicom da odgovor na pitanje koje su granice Balkana zavisi pre svega od pristupa koji izaberemo. U tom smislu možemo razlikovati Balkansko poluostrvo, kao termin koji pripada fizičkoj geografiji, od termina Balkan koji pripada političkoj geografiji. Ovu distinkciju u velikom broju svojih dela detaljno istražuje Milomir Stepić: „Balkansko poluostrvo je prvenstveno fizičko-geografski pojam, a granica na Savi i Dunavu predstavlja više istorijsko-civilizacijski relikat - jedan od mnogih u Evropi. Površina Balkanskog poluostrva je $520.000 \mathrm{~km}^{2}$ i manja je od prostora koji podrazumeva pojam Balkan. Balkan se razlikuje od Balkanskog poluostrva u teritorijalno-delimitacionom i kvalitativno-strukturalnom smislu. Sever-

${ }^{1}$ Isidora Sekulić, Analitički trenuci i teme, Vuk Karadžić, 1977, str. 17. 
na granica Balkana poklapa se sa severnom granicom Rumunije i nekadašnje „druge“ Jugoslavije. U njegovom sastavu su Grčka, Albanija, Bugarska, Rumunija, evropski deo Turske (23.764 km $\mathrm{km}^{2}$ od ukupno $779.452 \mathrm{~km}^{2}$ površine Turske) i države nastale razbi-raspadom SFRJ - Srbija, Crna Gora, Makedonija, Bosna i Hercegovina, Hrvatska i Slovenija. Shodno tome, Balkan je političko-geografski pojam, koji podrazumeva teritoriju površine 788.770 km2.“2

Nastanak novog termina Zapadni Balkan dodatno komplikuje stvari. Ovaj termin je skovan od strane međunarodne zajednice kako bi definisale specifičan region koji obuhvata bivše države bivše Jugoslavije, bez Slovenije, sa Albanijom kako bi se ukazala tendencija na dalji tok evroatlantskog širenja. Termin je trebalo da razlikuje države članice EU od onih koje to još uvek nisu. lako se uglavnom nameće ideja da je ovaj termin pre svega ekonomska ili politička kategorija, ${ }^{3}$ njegova suština je pre svega geopolitička i geostrateška. Smatra se da površina Zapadnog Balkana obuhvata oko 264.000 kvadratnih kilometara, ali je čak i ova činjenica problematična i promenljiva. Republika Hrvatska je od početka bila veliki protivnik toga da se svrstava delom ovog regiona. Takav spoljno-politički stav je postao još snažniji posle završetka hrvatske integracije u EU, koji je označio da se službeno ona ne može više smatrati delom ove problematične konstrukcije. Ovaj ishod izaziva dodatna pitanja. Jedno od njih je svakako i da li će se države koje se integrišu u EU i dalje smatrati delom Zapadnog Balkana? Odgovor na sva ova pitanja je relevantan za razumevanje geopolitičkog pozicioniranja balkanskih zemalja u međunarodnim odnosima.

Sama pozicija Balkana prouzrokovala je da je tokom čitave svoje istorije privlačio pažnju svih velikih sila i njihove koncepcije „ulog je ceo svet”. Balkan leži na raskršću Evrope, Azije i Afrike. U tom kontekstu ovaj region je značajno mesto povezivanja mnogih civilizacija. I možda čuvena Cvijićeva ${ }^{4}$ konstatacija o tome da smo sagradili put na sred druma, iako veoma pojednostavljena, na najbolji način oslikava izazove sa kojima se balkanske države suočavaju tokom čitave svoje istorije, ali ujedno i geopolitičke i geostrateške aspiracije velikih sila prema ovom regionu. Zbog toga Milomir Stepić naglašava da Balkan predstavlja jednu od arena gde se „posredno testira snaga globalnih rivala. U stvari, odbijajući da se predaju bez borbe, svoje zadržavanje i destruktivno delovanje u Evroaziji SAD zasnivaju na održavanju nestabilnog, konfliktnog stanja unutar geografskog prostora Bliski Istok - Centralna Azija - Jugoistočna Evropa, tj. u trusnom geopolitičkom trouglu „Arabijska Velika pukotina“ (Mekinder) - „Evroazijski Balkan“ (Bžežinski) - „Balkanske kontrole Evroazije, koja je (samo) pitanje vremena i cene. ${ }^{\text {"5 }} \mathrm{Na}$ Balkanu su velike sile često nametale svoju ulogu zaštitnika, ali ne zbog altruističkih motiva, već pre svega kako bi uspostavile svoju geopolitičku i geostratešku poziciju u regionu. Kako je ekonomista Nikolas Gianiris [Nicholas V. Gianaris] slikovito opisao: „Velike sile su pronašle plodno tlo za svoj uticaj i sukobe, ali kako stara izreka kaže, kada se slonovi svađaju trava biva uništena. ${ }^{\text {“6 }}$ Tom prilikom termin balkanizacija poprima negativnu konotaciju

\footnotetext{
${ }^{2}$ Milomir Stepić, "Zapadni Balkan ili primer geopolitičkog manipulisanja“, CEPOM, dostupno na: http://www.ceopom-istina.rs/globalizam/politicki-procesi/zapadni-balkan-li-primer-geopolitichkog-manipulisan/?lang=lat; datum pristupa 05 June 2019

${ }^{3}$ Dejan Vuletić, "Nato i Zapadni Balkan”, Vojno delo, Ministarstvo odbrane Republike Srbije, 7/2018, p. 41.

${ }^{4}$ Jovan Cvijić, Balkansko poluostrvo i južnoslovenske zemlje, Narodna biblioteka Srbije, Beograd, 1922.

5 Milomir Stepić, „Deatlantizacijom do stabilizacije Balkana: srpski nacionalni interes“, Srpska politička misao, Institut za političke studije, Beograd, br. 1/2017, str. 9.

${ }^{6}$ Nicholas V. Gianaris, Geopolitical and Economic Changes in the Balkan Countries, PREAGER, Westport, Connecticut, London, 1996, p. xi
} 
koja se koristi da označi sukobe i fragmentacije širom sveta, dok se za Balkan neretko vezuje i kovanica bure baruta Evrope. Ovaj region veoma često umesto mosta između istoka i zapada postaje poprište sukoba između telurokratije (kopnene moći) i talasokratije (pomorske moći). Ovo je ujedno i razlog zbog koga su balkanski narodi veoma teško mogli da donose odluke u skladu sa sopstvenim nacionalnim interesima, već su pre svega morali da svoje interese prilagođavaju interesima velikih sila. „U savremenom dobu balkanski narodi su prošli period tranzicije od Istoka ka integraciji u evroatlatnske strukture. Kada je reč o ekonomiji pseudo-elite nekritički prate neoliberalni model zavisne modernizacije, dok u političkoj sferi teže liberalnom demokratskom višestranačkom parlamentarnom reprezentativnom sistemu. U sferi kulture oni prate duh anglosaksonske modernizacije i zavisne kulture. ${ }^{7}$

\section{Unutrašnji i spoljašnji izazovi koje Republika Srbija treba da prevaziđe u XXI veku u svom geopolitičkom pozicioniranju na Balkanu}

Ukoliko želimo da razumemo izazove sa kojima se Republika Srbija suočava se u XXI veku potrebno in je podeliti u nekoliko sfera. Kada se radi o unutrašnjim problemima tu pre svega ističemo političke, ekonomske i demografske, dok od spoljašnjih faktora najviše izazova stvaraju geopolitički i geostrateški uticaji velikih sila na ovim prostorima.

Kada se radi o političkim i ekonomskim izazovima Republika Srbija mora neprestano raditi na poboljšanju svojih demokratskih kapaciteta političkih institucija. „Srbija predstavlja slabu i nedovršenu državu koja je krajem XX i početkom XXI veka bila izložena brojnim izazovima, neoimperijalnim ambicijama velikih sila, regionalnim nestabilnostima, neoliberalnom modelu zakasnele, odložene i blokirane tranzicije koja je suštinski započela tek posle 2000. godine, kao i stalnim prekrajanjima granica." ${ }^{8}$ I mada je značajan korak učinjen u ovom pravcu potrebno je na tome još dosta raditi, naročito imajući u vidu da građani Srbije u velikoj većini smatraju da strane države i pojedinci imaju značajan uticaj na funkcionisanje političkih institucija Republike Srbije. „Demokratija se u tako kreiranom okviru suočava sa brojnim preprekama: institucije demokratije postaju fasada; političke odluke potiču od nekontrolisanih centara, privatnih učesnika i anonimnih tržišta; novac i lobiji se kamuflirani ulažu u stranke i izborne kampanje; dolazi do medijalizacije i manipulacija politike i razmaha političkog pokroviteljstva i klijentelizma. Posledično, gotovo zakonomerno na delu imamo i: ravnodušnost prema izbornim procesima i ograničeno učešće građana u političkom životu, neodgovornost stranaka prema zahtevima birača, kršenje ljudskih prava, koncentrisanje moći u elitističkim grupama, centralizaciju vlasništva, kontrolisanje masovnih medija i korupciju." ${ }^{\prime \prime}$ Što se tiče ekonomskih problema jedno od gorućih pitanja predstavlja problem siromaštva i nezaposlenosti uz neravnomerni regionalni

\footnotetext{
${ }^{7}$ Ljubiša R. Mitrović, "The Geopolitics of the Balkans in the 19th and 20th Centuries - Between National Emancipation Movements and Geostrategic Games of the Great Powers", Facta Universitatis, Faculty of Philosophy, University of Niš, 2/2011, p. 101.

${ }^{8}$ Živojin Đurić, Miša Stojadinović, „Država i neoliberalni modeli urušavanja nacionalnih političkih institucija“, Srpska politička misao, Institut za političke studije, Beograd, 4/2018, str. 41.

${ }^{9}$ Zoran Stojiljković, „Post(liberalna) demokratija, kapitalizam i kriza države“, Urušavanje ili slom demokratije? (urednici llija Vujačić i Bojan Vranić), Udruženje za političke nauke i Srbiji i Fakultet političkih nauka, Beograd, 2016, str. 18.
} 
razvoj. I mada se dosta toga radi i na ovome, imajući u vidu da su to problemi sa kojima se Republika Srbija suočava dugi niz godina, potrebno je ipak uložiti jače napore uz jednu dugoročnu strategiju koja bi umanjila negativne trendove do kojih ovakvo stanje može da doprinese. Kako bi to bilo moguće treba napomenuti da siromaštvo selektivno pogađa različite društvene grupe i da je s tim u vezi potrebno uskladiti ekonomsku politiku kako bi se sa ovim problemom najefikasnije izborili. „U glavnom su to lica sa niskim nivoom obrazovanja, nezaposlena i izdržavana lica, stari (preko 65 godina), deca, kao i one grupe koje su tradicionalno među ugroženima, poput Roma, izbeglica i raseljenih lica, osoba sa invaliditetom, žene. Treba napomenuti da se mladi takođe ubrajaju u osetljive kategorije siromašnih, a takođe i to da siromaštvo u Srbiji predstavlja i ruralni fenomen, odnosno selektivno pogađa seoske sredine, pre svega staračka domaćinstva. Kada se radi o regionalnom pregledu problema siromaštva treba istaći da ono najviše pogođeni jugoistok Srbije i ruralna područja Zapadne Srbije. “10

Demografski izazov sa kojim se suočava Republika Srbija je veoma zabrinjavajući. Između dva poslednja popisa stanovnika Republika Srbija je izgubila 311.139 građana, što zajedno sa činjenicom demografskog starenja stanovništva predstavlja veliku problem. Za bolje razumevanje demografskog starenja u Srbiji bitno je sagledati brzinu kojom se ovaj proces odvijao (Tabela 1).

Tabela 1 - Broj stanovnika Republike Srbije u periodu 1948-2011.

\begin{tabular}{|c|c|c|c|c|c|c|c|c|}
\hline & 1948 & 1953 & 1961 & 1971 & 1981 & $1991^{2}$ & 2002 & 2011 \\
\hline РЕПУБЛИКА СРБИJА / REPUВLIC OF SERBIA & 6527966 & 6979154 & 7642227 & 8446591 & 9313676 & 7822795 & 7498001 & 7186862 \\
\hline Срби / Serbs & 4823730 & 5152939 & 5704686 & 6016811 & 6182155 & 6252405 & 6212838 & 5988150 \\
\hline Албанци³) / Albanians3) & 532011 & 565513 & 699772 & 984761 & 1303034 & 78281 & 61647 & 5809 \\
\hline Бошњаци / Bosniaks & - & - & - & - & - & - & 136087 & 145278 \\
\hline Бyrapu / Bulgarians & 59472 & 60146 & 58494 & 53800 & 33455 & 26698 & 20497 & 18543 \\
\hline Буњевци4) / Bunjevci"s? & - & - & - & - & - & 21434 & 20012 & 16706 \\
\hline Власи / Vlachs & 93440 & 28047 & 1368 & 14724 & 25596 & 17804 & 40054 & 35330 \\
\hline Горанци / Goranci & - & - & - & - & - & - & 4581 & 7767 \\
\hline Југословени5) / Yugoslavs9 & - & - & 20079 & 123824 & 441941 & 320168 & 80721 & 23303 \\
\hline Małapu / Hungarians & 433701 & 441907 & 449587 & 430314 & 390468 & 343800 & 293299 & 253899 \\
\hline Македонци / Macedonians & 17917 & 27277 & 36288 & 42675 & 48986 & 45068 & 25847 & 22755 \\
\hline Муслимани' / Muslims' & 17315 & 81081 & 93467 & 154330 & 215166 & 180222 & 19503 & 22301 \\
\hline Hемци / Germans & 41460 & 46228 & 14533 & 9086 & 5302 & 5172 & 3901 & 4064 \\
\hline Poми / Roma people & 52181 & 58800 & 9826 & 49894 & 110959 & 94492 & 108193 & 147604 \\
\hline Румуни / Romanians & 63130 & 59705 & 59505 & 57419 & 53693 & 42316 & 34576 & 29332 \\
\hline Pycu / Russians & 13329 & 7829 & 6984 & 4746 & 2761 & 2473 & 2588 & 3247 \\
\hline Русини / / Ruthenians? & 22667 & 23720 & 25658 & 20608 & 19757 & 18052 & 15905 & 14246 \\
\hline Словаци / Slovaks & 73140 & 75027 & 77837 & 76733 & 73207 & 66772 & 59021 & 52750 \\
\hline Словенци / Slovenians & 20998 & 20717 & 19957 & 15957 & 12006 & 8001 & 5104 & 4033 \\
\hline Украјинцй) / Ukrainians? & $\ldots$ & $\ldots$ & $\ldots$ & 5643 & 5520 & 5042 & 5354 & 4903 \\
\hline Хрвати / / Croats & 169864 & 173246 & 196409 & 184913 & 149368 & 97344 & 70602 & 57900 \\
\hline Црногорци / Montenegrins & 74860 & 86061 & 104753 & 125260 & 147466 & 118934 & 69049 & 38527 \\
\hline Остали / Other & 18751 & 68917 & 57420 & 29924 & 34931 & 14800 & 13922 & 17558 \\
\hline Нису œе изјаснили / Did not declare & - & - & - & 4486 & 7834 & 10718 & 107732 & 160346 \\
\hline Регионална припадност / Regional affiliation & - & - & - & 10409 & 6848 & 4841 & 11485 & 30771 \\
\hline Непознато ${ }^{8} /$ Unknown ${ }^{8)}$ & $\ldots$ & 1994 & 5604 & 30274 & 43223 & 47958 & 75483 & 81740 \\
\hline
\end{tabular}

(Izvor: Census of Population, Households and Dwellings in the Republic of Serbia 2011, Statistical Office of the Republic of Serbia, Belgrade, 2012)

\footnotetext{
${ }^{10}$ Marija Kolin, Jasna Kronja, Jelena Milovanović, Zoran Stojiljković, Socijalni dijalog i socijalna politika u Srbiji u procesu evropske integracije, Evropski pokret Srbija i Friedrich Ebert Stiftung, Beograd, decembar 2006, str. 27.
} 
Ukoliko poredimo bazni indeks promene ukupnog stanovništva Srbije i bazni indeks promene stanovništva starijeg od 65 godina može se na najbolji način videti problem demografskog starenja populacije Republike Srbije. „Jaz između vrednosti dva posmatrana indeksa je sa svakim popisom bio sve veći. Na osnovu kretanja i međuodnosa dva indeksa, uslovno se mogu izdvojiti četiri perioda. Prvi je do 1961. godine, kada su razlike porasta ukupnog i starog stanovništva bile najmanje, drugi od 1961. do 1991, kada se porast starijih znatno ubrzava, period od 1991. do 2002, kada se uspostavljaju divergentni tokovi (dok ukupno stanovništvo opada, staro ostvaruje eksponencijalni porast), i poslednji, u kojem Srbija i dalje gubi stanovništvo, a porast kontingenta starih se usporava."

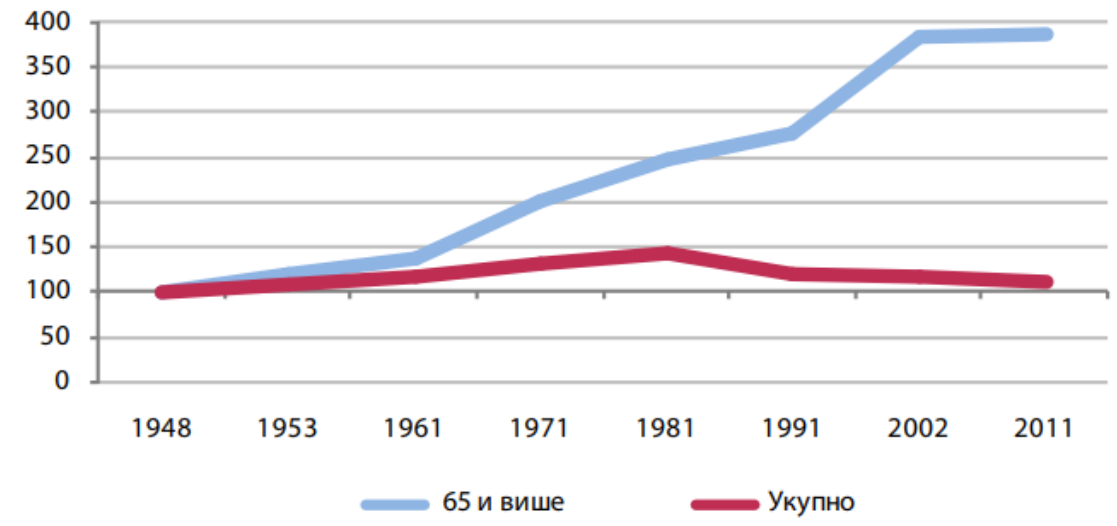

Grafikon 2 - Indeks promene ukupnog stanovništva i stanovništva starosti 65 i više godina, popisi 1948-2011, $1948=100 \%$

(Izvor: Mirjana Devedžić, Jelena Stojilković Gnjatović, „Popis stanovništva, domaćinstava i stanova 2011

u Republici Srbiji - demografski profil starog stanovništva Srbije“ Republički zavod za statistiku,

Beograd, 2015, str. 31)

Evrostat nema nimalo ohrabrujuće projekcije demografske slike Srbije u budućnosti: „Srbija će do 2060, prema očekivanjima evropske statističke agencije Evrostat, imati 21 odsto stanovnika manje nego 2015. godine, što je svrstava među evropske zemlje sa najvećim očekivanim smanjenjem broja stanovnika, rečeno je na jučerašnjem panelu o demografskim promenama u Srbiji. “12 Najnovije izjave Republičkog zavoda za statistiku takođe deluju zabrinjavajuće: „Poslednji raspoloživi podaci iz 2017. godine pokazuju da se trend snažnog i kontinuiranog procesa demografskog starenja u Srbiji nastavlja. Prosečna starost u Srbiji 2017. iznosila je 43 godine, a udeo u stanovništvu starijih od 65 godina dostigao je 19,6 odsto." ${ }^{\text {"13 }}$ Njihove procene kada se radi o budućim projekcijama

\footnotetext{
${ }^{11}$ Mirjana Devedžić, Jelena Stojilković Gnjatović, „Popis stanovništva, domaćinstava i stanova 2011 u Republici Srbiji - demografski profil starog stanovništva Srbije" Republički zavod za statistiku, Beograd, 2015, str. 30.

${ }^{12}$ Drastično opada broj stanovnika u Srbiji, evo koliko će nas biti 2060, B92, dostupno na https://www.b92.net/zivot/vesti.php?yyyy=2019\&mm=01\&dd=24\&nav_id=1496986, datum pristupa 30. jun 2019. ${ }^{13}$ Isto.
} 
ukazuju da će 2060. gotovo svaki treći stanovnik biti stariji od 65 godina. To govori o potrebi da se sprovodi agresivnija populaciona politika koja će morati da se uskladi sa ovim dugogodišnjim negativnim trendovima i da im odgovori na pravi način. Zbog toga je potrebno raditi na poboljšanju mera populacione politike koje će favorizovati i podsticati rađanje, jer to je jedini pravi put za budućnost.

Kada se radi o geopolitičkom izazovu Republika Srbija se nalazi rastrzana između dva potpuno suprotstavljena geopolitička koncepta: evroatlantskog i evroazijskog. Republika Srbija se nalazi na razmeđu Jugoistočne i Centralne Evrope. Graniči se sa Bugarskom, Hrvatskom, Bosnom i Hercegovinom, Mađarskom, Crnom Gorom, Severnom Makedonijom, Rumunijom i Albanijom. Centralna pozicija na Balkanu je prouzrokovala i turbulentnu istoriju ispunjenu pretenzijama velikih sila na ovim prostorima ispunjene stalnim dezintegrativnim procesima. ${ }^{14}$ Čak i ako bi se fokusirali samo na period početka XXI veka može se videti jedno konstantno prekrajanje granica koje se možda najbolje može opisati slikoviti terminom razbiraspad Miloša Kneževića, ${ }^{15}$ koji je njime opisivao raspad Jugoslavije. Dezintegracija se nastavlja i u novom milenijumu. Savezna Republika Jugoslavija je 2003. godine prestala da postoji i nova država Srbija i Crna Gora je rođena. Ova tvorevina je takođe bila kratkog daha jer je samo tri godine kasnije ona prestala da postoji jer je Crna Gora formalno proglasila nezavisnost 03. juna 2006. godine. Time se, međutim, dezintetrativni proces na ovim prostorima ne završava jer južna provincija Kosovo i Metohija 17. februara 2008. godine samo-proglašava nezavisnost i novo mesto zamrznutog konflikta je otvoreno. Ova najnovija pandorina kutija koja je stvorena na našim prostorima je dovela do dalekosežnih posledica na koje ni njeni tvorci na čelu sa SAD nisu računali. Dvostruki aršini međunarodnog prava na našim prostorima doveli su do toga da je ono postalo sredstvo demonstracije moći. To se može videti i na osnovu pregovora koji se odvijaju na relaciji Beograd-Priština, gde se druga strana maksimalno favorizuje i, kada tzv. „Republika Kosovo“ napravi nešto što je u suprotnosti sa dogovorenim (uvođenje sankcija na proizvode iz Srbije i Bosne i Hercegovine, upad ROSU na sever Kosova, stvaranje generalno nepodnošljivih uslova za život Srba na severu Kosova...), ništa drugo od blage osude ne biva urađeno kako bi se opasna situacija, kako tako, vratila na neki normalan kolosek.

Srbija u XXI veku pokušava da pronađe svoju poziciju u međunarodnim odnosima sledeći principe neutralnosti na svom kursu ka evropskim integracijama. Ovde se međutim javljaju mnogobrojni problemi koji proizilaze iz geopolitičke složenosti situacije. Jedna od njih je svakako da je Srbija okružena NATO članicama što stvara dodatni pritisak na održivost politike neutralnosti, a drugi je pitanje kako bi se evropske integracije sprovele u praksi? Svedoci smo mnogobrojnih uslovljavanja na ovom putu kojima se ne nazire kraj. Prvi i osnovni problem je što postoji veliki pritisak da se evropske integracije završe priznavanjem nezavisnosti tzv. „Republike Kosova“. Drugi veliki problem koji se javlja jeste da bi to u velikoj meri pogoršalo odnose sa Rusijom. Srbija bi najverovatnije bila prinuđena da se pridruži ekonomskim sankcijama Rusiji. Doduše ni države članice EU nisu jedinstvene po ovom pitanju jer i one mnogo gube ovim sankcijama koje su pod prinudom SAD morale da uvedu, ne samo ekonomski, nego i energetski. Nezahvalan položaj koji Republiku Srbiju di-

\footnotetext{
${ }^{14}$ O tome opširnije videti: Miša Stojadinović, „Srbija pred izazovima“, Srpska politička misao, Institut za političke studije, Beograd, 3/2009.

${ }^{15}$ Miloš Knežević, „Tranzicija i geopolitika u novom ključu, Godišnjak za sociologiju, Filozofski fakultet, Niš, 10-11/2012, str. 173.
} 
rektno vodi u sukobljenost dva različita geopolitička koncepta nameće jedno na prvi pogled nezamislivo rešenje, a to je spajanje nespojivog. „Prihvatanjem samo jednog od geopolitičkih koncepata (evroatlantskog ili evroazijskog) Republika Srbija bi imala mnogo toga da izgubi, pa je jedino rešenje u tome da ona održi svoju politiku neutralnosti u pokušaju da predstavlja neki vid mosta između ova dva nepomirljiva koncepta. (...) I možda je to teži put kojim je potrebno poći, ali treba uvek imati na umu da postoje uspešni primeri koji su na svoj način uspele da izbore svoje mesto unutar Evropske unije kao neutralne države (Švajcarska, Švedska, Finska i Austrija)." ${ }^{\text {'16 }}$ Izgradnja mosta između Istoka i Zapada, najbolje demonstrirana, sa jedne strane u inicijativi Pojas i put, i sa druge strane u izgradnji Turskog toka, koji mogu demonstrirati zajednički interes dva nepomirljiva faktora, a koji može proizaći iz zajedničke ekonomske i energetske saradnje.

\section{Izazovi uspostavljanju regionalne saradnje na koje Republika Srbija treba da računa}

Jedan od najvećih izazova koji Republika Srbija treba da prevaziđe na putu ostvarivanja regionalne saradnje je nedostatak tradicije multilateralne saradnje na Balkanu uz prevelik broj dugogodišnjih nerešenih nesuglasica i konflikata. Činjenica da ovaj region karakterišu multinacionalnost, multikonfesionalnost i multikulturalnost dodatno komplikuje stvari po pitanju prevazilaženja razlika u cilju uspostavljanja međusobne saradnje. U ovom kontekstu treba istaći da kultura mira na Balkanu nikada nije uspela da se uspostavi. Međusobne razlike su neretko bile zloupotrebljavane kao izvor mnogobrojnih društvenih, političkih i međudržavnih sukoba u različitim istorijskim periodima, što je dodatno uzrokovalo slabljenje kapaciteta regionalne saradnje na Balkanu. Insistiranje na kulturi dijaloga i tolerancije, uz korišćenje svih sredstava tzv. meke moći [Joseph Nye] ${ }^{17}$ i mekog balansiranja [T.V. Paul] ${ }^{18}$, a naročito javne diplomatije, treba biti jedini put Republike Srbije. Ovo je naročito važno jer dok se potreba za dijalogom i tolerancijom među balkanskim zemljama povećavala, praksa je pokazala da se njihova primena sve više smanjivala. „Balkanski nacionalizmi su bili presudni za procese izgradnje nacionalne države u regionu, ali su oni ujedno viđeni i kao izvori ozbiljnih poteškoća na Balkanu koji stvaraju opstrukcije za razvoj i dobrobit regiona. Događaji posle Hladnog rata samo su dodatno opravdavali tu percepciju i zbog neskladnih balkanskih nacionalizama ovaj region je još jednom označen kao bure baruta Evrope. Posebno snažan doprinos tom imidžu pružio je eksplozivni raspad Jugoslavije kada su balkanski nacionalizmi ponovo bili konstituisani kao glavni krivci." Posledica ovakvog stanja je da na ovim prostorima isuviše dugo nije uspostavljen Galtungov [Johan Galtung] koncept pozitivnog mira. ${ }^{19}$ Prema rečima Ljubiše Mitrovića „Kultura mira, zajedno sa socijaldemokratskom

\footnotetext{
${ }^{16}$ Miša Stojadinović, „Evropa i multipolarni svet“, Politika nacionalne bezbednosti, Institut za političke studije, Beograd, 1/2018, str. 169.

${ }^{17}$ Joseph Nye, Bound To Lead: The Changing Nature Of American Power, Basic Books; Reprint edition, 1991.

${ }^{18}$ T.V. Paul, Restraining Great Powers Soft Balancing from Empires to the Global Era, Yale University Press, London, 2018, p. 22.

${ }^{19}$ Johan Galtung, „Peace and Conflict Studies as Political Activity“, Critical Issues in Peace and Conflict Studies (eds. Thomas Matyók, Jessica Senehi and Sean Byrne ), LEXINGTON BOOKS, 2011.
} 
strategijom održivog i humanog razvoja, može doprineti globalizaciji razumevanja i solidarnosti među narodima. Ona bi mogla da vrati veru balkanskih naroda u sebe, u svoje susede i u demokratsku budućnost Balkana. Takođe, bi se potvrdili principi jednakosti svih građana i naroda, poštovanje dijaloga različitih kultura i partnerstvo civilizacija, a sve to je zajednički strateški interes svih balkanskih naroda..."

Jedini način da Republika Srbija istraje na ovom putu jeste konstantno jačanje demokratskih i nacionalnih kapaciteta svojih političkih institucija. Ovo zahteva temeljnu promenu sistema vrednosti kroz jedan radikalni rez koji će označiti poboljšanje najpre pogranične saradnje sa svim država susedima. Ovako nešto, međutim, zahteva sličan smer spoljne politike i drugih država suseda na putu izgradnje pluralističkog identiteta koji će omogućiti nastanak povoljne klime za međusobni dijalog i saradnju. Jačanje regionalne saradnje je jedini način da se prevaziđe potčinjenost interesima velikih sila u večitom sukobu Istoka i Zapada. Međutim, regionalna saradnja se konstantno nalazi pred brojnim unutrašnjim poteškoćama koje proizilaze iz prirode odnosa između balkanskih zemalja, a koje u svom radu sumiraju Duško Lopandić i Jasminka Kronja, a to su: „nedostatak tradicije multilateralne saradnje; nerazvijene ekonomije i ograničeni resursi za saradnju (finansijski i ljudski); periferna pozicija regiona u poređenju sa evropskim centrima za integraciju, zajedno sa glavnom tendencijom većine država u regionu za političku i ekonomsku saradnju i integraciju sa razvijenim zapadnim državama; dugotrajni i nerešeni regionalni sporovi i sukobi uključujući sporove oko granica ili nacionalnih manjina; politička i ekonomska nepovezanost; i razlike u nacionalnim, političkim i ekonomskim interesima." ${ }^{21}$ Ukoliko se ovakva situacija ne promeni ostvarivanje regionalne saradnje će biti veoma otežano, naročito imajući u vidu da je percepcija razlika u nacionalnim, političkim i ekonomskim interesima balkanskih zemalja sasvim pogrešna. Dokle god postoji ovakvo viđenje balkanskih zemalja šira slika ekonomskih i političkih koristi koje međusobna saradnja može da donese nikada neće biti okosnica jačanja kvaliteta njihovog međusobnog odnosa. „Stran svet i strani političari obično nemaju nikakvo, ili imaju samo slabo, znanje i iskustvo balkansko. A ako ga imaju kakvo takvo, iz posebnih političkih razloga prikazuju Balkan uvek kao razbijen brod, koji još i dalje ljulja bura nesloge i netrpeljivosti i koji neminovno mora da drži neko spolja, da ne potone. "22 To je razlog više da balkanski narodu uzmu sudbinu u svoje ruke kako bi se ovaj razbijeni brod, kako ga Isidora Sekulić prikazuje u očima drugih, vrati na pravi kurs, a Republika Srbija, sa svojom centralnom pozicijom, može odigrati značajnu ulogu u uspostavljanju mosta regionalne saradnje svih balkanskih zemalja.

\section{Literatura}

[1] Devedžić Mirjana, Gnjatović Stojilković Jelena, „Popis stanovništva, domaćinstava i stanova 2011 u Republici Srbiji - demografski profil starog stanovništva Srbije“ Republički zavod za statistiku, Beograd, 2015.

[2] Drastično opada broj stanovnika u Srbiji, evo koliko će nas biti 2060, B92, dostupno na https://www.b92.net/zivot/vesti.php?yyyy=2019\&mm=01\&dd=24\&nav_id=1496986, datum prostupa 30. jun 2019.

\footnotetext{
${ }^{20}$ Ljubiša R. Mitrović, "The Geopolitics of the Balkans in the 19th and 20th Centuries - Between National Emancipation Movements and Geostrategic Games of the Great Powers", op.cit. p. 101.

${ }^{21}$ Duško Lopandić, Jasminka Kronja, Regional Initiatives and Multilateral Cooperation in the Balkans, European Movement, Serbia, Belgrade, 2011, p. 25.

${ }^{22}$ Isidora Sekulić, Analitički trenuci i teme, op. cit. str. 17.
} 
[3] Galtung Johan, „Peace and Conflict Studies as Political Activity“, Critical Issues in Peace and Conflict Studies (eds. Thomas Matyók, Jessica Senehi and Sean Byrne ), LEXINGTON BOOKS, 2011.

[4] Gianaris V. Nicholas, Geopolitical and Economic Changes in the Balkan Countries, PREAGER, Westport, Connecticut, London, 1996.

[5] Google Maps, dostupno na:

https://www.google.com/maps/place/Balkans/@42.1141537,20.424738,6.25z/data=!4m5!3m4!1s0x1356 8040c2 11aea7:0xfdffff63490b475d!8m2!3d41.8101472!4d21.0937311, datum pristupa 26 maj 2019.

[6] Đurić Živojin, Stojadinović Miša, „Država i neoliberalni modeli urušavanja nacionalnih političkih institucija“, Srpska politička misao, Institut za političke studije, Beograd, 4/2018.

[7] Knežević Miloš, „Tranzicija i geopolitika u novom ključu, Godišnjak za sociologiju, Filozofski fakultet, Niš, 10-11/2012.

[8] Kolin Marija, Kronja Jasna, Milovanović Jelena, Zoran Stojiljković, Socijalni dijalog $i$ socijalna politika u Srbiji u procesu evropske integracije, Evropski pokret Srbija i Friedrich Ebert Stiftung, Beograd, decembar 2006.

[9] Lopandić Duško, Kronja Jasminka, Regional Initiatives and Multilateral Cooperation in the Balkans, European Movement, Serbia, Belgrade, 2011.

[10] Mitrović R. Ljubiša, "The Geopolitics of the Balkans in the 19th and 20th Centuries Between National Emancipation Movements and Geostrategic Games of the Great Powers", Facta Universitatis, Faculty of Philosophy, University of Niš, 2/2011.

[11] Nye Joseph, Bound To Lead: The Changing Nature Of American Power, Basic Books; Reprint edition, 1991.

[12] Paul T.V., Restraining Great Powers Soft Balancing from Empires to the Global Era, Yale University Press, London, 2018.

[13] Sekulić Isidora, Analitički trenuci i teme, Vuk Karadžić, 1977.

[14] Stepić Milomir, „Deatlantizacijom do stabilizacije Balkana: srpski nacionalni interes“, Srpska politička misao, Institut za političke studije, Beograd, br. 1/2017.

[15] Stepić Milomir, "Zapadni Balkan ili primer geopolitičkog manipulisanja", CEPOM, dostupno na: http://www.ceopom-istina.rs/globalizam/politicki-procesi/zapadni-balkan-ili-primer-geopolitichkogmanipulisan/?lang=lat; datum pristupa 05 June 2019.

[16] Stojadinović Miša, „Evropa i multipolarni svet“, Politika nacionalne bezbednosti, Institut za političke studije, Beograd, 1/2018.

[17] Stojadinović Miša, „Srbija pred izazovima”, Srpska politička misao, Institut za političke studije, Beograd, 3/2009.

[18] Stojiljković Zoran, „Post(liberalna) demokratija, kapitalizam i kriza države“, Urušavanje ili slom demokratije? (urednici llija Vujačić i Bojan Vranić), Udruženje za političke nauke i Srbiji i Fakultet političkih nauka, Beograd, 2016.

[19] Census of Population, Households and Dwellings in the Republic of Serbia 2011, Statistical Office of the Republic of Serbia, Belgrade 2012.

[20] Cvijić Jovan, Balkansko poluostrvo i južnoslovenske zemlje, Narodna biblioteka Srbije, Beograd, 1922. 